\title{
Association between head circumference at two years and second and fifth year cognition
}

\author{
Beena Koshy ${ }^{1 *}$, Manikandan Srinivasan², Timiri Palani Murugan ${ }^{1}$, Anuradha Bose ${ }^{3}$, Pamela Christudoss ${ }^{4}$, \\ Venkata Raghava Mohan ${ }^{3}$, Sushil John', Reeba Roshan ${ }^{1}$ and Gagandeep Kang ${ }^{2}$
}

\begin{abstract}
Background: Head circumference $(\mathrm{HC})$ measurement is routinely not performed in early childhood and there is conflicting information about its utility in literature. The current study analyses the association between $\mathrm{HC}$ at two years of age and cognition at two and five years of age.

Methods: A community based birth-cohort recruited between 2010 and 2012 was followed up till five years of age in an urban slum in Vellore, India. Children were recruited at birth after informed parental consent by consecutive sampling using eligibility criteria of healthy new-born, singleton pregnancy and family's availability in the study area during follow-up. HC measured at two years of age was used as the exposure variable to calculate association with cognition at both two and five years of age. Cognitive domain of Bayley scale of infant development was used at two years of age and Wechsler Preschool Primary Scales of Intelligence at five years.

Results: Of the 251 enrolled children, 138 (55\%) were girls and 71 (30\%) belonged to lower socioeconomic status. At 2 years, $8.81 \%$ of children had $\mathrm{HC}<-3 \mathrm{SD}$. Compared to children with $\mathrm{HC} z$-scores $\geq-2 \mathrm{SD}$, those with measurements $<-3$ SD had a lower cognition scores by -2.21 [95\% Cl: $-3.87--0.56]$ at 2 years. Also, children with $\mathrm{HC}<-3$ SD at two years scored significantly lower scores in cognitive domains of verbal, -7.35 [95\% Cl: $11.78--2.92]$ and performance, -7.07 [95\% Cl: $-11.77--2.36]$ intelligence at five years.

Conclusions: This study showed that smaller $\mathrm{HC}$ at 2 years of age was negatively associated with cognition at both 2 and 5 years of age. Early childhood HC measurements can be utilised as a cheaper screening tool to identify children at risk in LMIC settings. Further studies can confirm these findings in diverse settings.
\end{abstract}

Keywords: Early childhood, Head circumference, Cognition

\section{Introduction}

Children growing up in vulnerable backgrounds including low and middle income country (LMIC) settings are at risk of growth and development faltering, necessitating their close monitoring $[1,2]$. Anthropometric measurements in children including height, weight and head

\footnotetext{
* Correspondence: beenakurien@cmcvellore.ac.in

'Developmental Paediatrics Unit, Christian Medical College, Vellore 632004, India

Full list of author information is available at the end of the article
}

circumference $(\mathrm{HC})$ measurements are used to gauge their maturational processes during childhood, and their close monitoring can identify early faltering necessitating appropriate and timely interventions [1]. Though height and weight are routinely measured in general paediatric clinics and immunisation centres, $\mathrm{HC}$ measurements are not consistently performed $[3,4]$. HC measurement in early childhood/infancy reflects brain volume and growth in lieu of open cranial sutures and fontanelles;

(c) The Author(s). 2021 Open Access This article is licensed under a Creative Commons Attribution 4.0 International License, which permits use, sharing, adaptation, distribution and reproduction in any medium or format, as long as you give appropriate credit to the original author(s) and the source, provide a link to the Creative Commons licence, and indicate if changes were made. The images or other third party material in this article are included in the article's Creative Commons licence, unless indicated otherwise in a credit line to the material. If material is not included in the article's Creative Commons licence and your intended use is not permitted by statutory regulation or exceeds the permitted use, you will need to obtain permission directly from the copyright holder. To view a copy of this licence, visit http://creativecommons.org/licenses/by/4.0/ The Creative Commons Public Domain Dedication waiver (http://creativecommons.org/publicdomain/zero/1.0/) applies to the data made available in this article, unless otherwise stated in a credit line to the data. 
and can be a valuable tool to analyse brain growth and development in this age group [5, 6].

Studies evaluating the utility of $\mathrm{HC}$ measurements in childhood have produced mixed results. Many studies found routine $\mathrm{HC}$ measurement in typically developing children unnecessary, and suggested $\mathrm{HC}$ monitoring in instances where measurements were above +2 SDs $[5,7$, 8]. In children at risk, including those exposed to alcohol during prenatal period [9], born as a preterm [10, 11] and having very low birth weight [12], HC was shown to be related to cognition/development. Similar findings have been reported from typically developing children with evidences from a large multinational LMIC community based birth-cohort study [2], and from cohort studies in India [13], UK [14], Israel [15] and Uruguay [16]. An Indian birth-cohort study showed HC at birth was related to learning, memory and storage and visuospatial abilities around 10 years of age [13].

These diverging findings might be due to the timing of $\mathrm{HC}$ measurements and differing characteristics of the cohorts studied [5, 7-10, 12-14]. Relationship between $\mathrm{HC}$ and whole-brain volume is variable through human life with $\mathrm{HC}$ being an excellent predictor of brain volume in early childhood [17]. Once sutures and fontanelles close, HC remains almost unchanged, and does not reflect the later brain volume changes including agedependent atrophy in later life.

With this background, we propose to assess the relationship between $\mathrm{HC}$ measured at two years and cognition at two and five years of age in a birth-cohort in south India. Two years is considered the culmination of the first 1000 days of life [18] and five years symbolises the end of the next 1000 days [19]; both signifying rapid brain growth and development. It is hypothesised that the two year $\mathrm{HC}$ measurement will be associated with both cognition at two and five years of age.

\section{Methods}

\section{Settings and subjects}

The current study was done as an independent subanalysis of a large multinational prospective, longitudinal birth-cohort study in eight different countries across the world -The Etiology, Risk Factors and Interactions of Enteric Infections and Malnutrition and the Consequences for Child Health and Development (MAL-ED) Network' [20]. The Indian study was conducted in a densely populated urban slum in Vellore, South India [21]. The population of 12,000 was covered prior to enrolment and pregnant women were identified by a doorto-door survey. Consenting mothers were invited by consecutive sampling to participate in the study immediately after birth, after an informed consent. The exclusion criteria included family's existing plans to migrate out of the study site during the study period, multiple pregnancies, medical comorbidities in the index child, another child from the same family already registered in the study, and mothers unavailable to provide necessary consent. Trained field workers visited the recruited children twice a week till their second birthday for active disease surveillance and growth monitoring as per the MAL-ED protocol, with subsequent follow-ups. The initial birth-cohort recruitment in Vellore was between March 2010 and February 2012 and enrolled 251 newborns. The original birth-cohort enrolment and subsequent follow-ups were approved by the Institutional Review Board and Ethics Committee of Christian Medical College, Vellore and children were recruited at each stage after informed parental consent.

\section{Measures}

Anthropometric measurements were performed monthly for all children till two years of age. Length was measured using an infantometer to the nearest $\mathrm{cm}$ and weight using an electronic weighing scale to the nearest $10 \mathrm{~g}$. HC was measured by a trained study nurse using a non-stretchable tape to the nearest $0.1 \mathrm{~cm}$. Quality control was assured by periodic retraining and recalibration of machines as per the MAL-ED study protocol. We used Multicentre Growth Reference Study (MGRS) standards to calculate $\mathrm{z}$-scores for height for age and the WHO growth standards for head circumference measurements respectively [22, 23].

\section{Bayley scales of infant and toddler development-III (BSID- III)}

The Bayley Scales of Infant and Toddler DevelopmentIII (BSID-III) is a developmental measure and assesses motor, language, cognition and social skills development between 1 and 42 months of age [24]. The BSID-III was culturally adapted, translated, back-translated and piloted, prior to its administration; and testing was conducted by a single trained clinical psychologist. Around $10 \%$ of assessments were video-recorded and reviewed locally for quality control and 5-6\% reviewed centrally by the central cognition team [25]. Cognition component of BSID-III measures exploration and manipulation of toys, concept formation, object relatedness and memory; and its raw scores at two years of age were utilised for current analysis.

\section{Wechsler preschool primary scales of intelligence-third edition (WPPSI-III)}

The Wechsler Preschool Primary Scales of Intelligence third edition (WPPSI-III) was used to assess cognition at five year of age [26]. This measure was adapted centrally for cultural appropriateness and was translated and piloted in local settings before being administered by a single trained psychologist. Verbal, performance and 
processing speed raw scores were obtained after administration for each child. For quality control, around 10\% of assessments were recorded and reviewed centrally.

\section{The WAMI measure for socio-economic status}

The WAMI measure is a composite measure of socioeconomic status (SES) developed during the MAL-ED study, with components of access to improved Water and sanitation, Assets, Maternal education and total household Income [27]. A trained field worker visited the home and administered the translated and piloted WAMI measure at six-monthly intervals till 24 months. The final score calculated from these variables was converted to a standardized score ranging from 0 to 1 .

\section{Raven's progressive matrices}

The Raven's progressive matrices is a measure of nonverbal reasoning ability [28]. This test was administered by a trained psychologist to mothers to assess maternal cognition at 6-8 months of child's age, as per the MALED study protocol [25]. Raw scores were used for analyses.

\section{Blood collection and analysis}

Blood samples were collected at 7, 15, 24 and 36 months of age in children. Ferritin and transferrin assays were done at 7, 15 and 24 months, and blood lead levels at 15, 24 and 36 months. The blood samples were immediately refrigerated using cold packs and transported to the research lab within two hours of blood collection. Ferritin and transferrin receptors were analysed using chemiluminescence immunoassay and immunoturbidimetry respectively, and blood lead level using Graphite Furnace Atomic Absorption Spectroscopy method in the Biochemistry department. Considering the influence of systemic inflammation on ferritin levels, we used a composite index based on both ferritin (F) and transferrin (T) levels to estimate the total body iron stores, with a positive value denoting surplus iron reserve [29].

$$
\operatorname{Body} \operatorname{Iron}(\mathrm{mg} / \mathrm{kg})=\left(\frac{-\left(\log \left(\frac{R}{F} \text { ratio }\right)-2.8229\right)}{0.1207}\right)
$$

\section{Data entry and analysis}

Using a double entry database system managed by the Data Co-ordinating Centre of the MAL-ED study, information collected in paper forms were entered into electronic database [20]. Completed paper forms were validated by field supervisor before data entry.

\section{Statistical analysis}

Categorical variables were expressed in percentages and continuous variables as mean (standard deviation) or median (range). Anthropometry measurements such as $\mathrm{z}$-scores of $\mathrm{HC}$, height-for-age, weight-for-age and weight-for-height were categorized into $>=-2 \mathrm{SD},-2$ to $-3 \mathrm{SD}$ and $<-3 \mathrm{SD}$. Using the 33rd percentile of WAMI scores as the cut-off, children were classified into low ( $<33$ rd percentile) and high $(>=33$ rd percentile) SES. Mean body iron and lead levels were calculated as average of measurements recorded at 7, 15 and 24; and, 15,24 and 36 months; respectively. Demographic and anthropometric characteristics during enrolment, 2 and 5 years of the cohort were compared using Chi-squared statistics. Using simple linear regression, we modelled the effect of 24-month $\mathrm{HC}$ on cognition scores measured at 2 and 5 years, after adjusting for variables such as - sex, height-for-age scores at 24 months, mother's cognition, SES, mean iron and lead levels. Blood lead levels, body iron and height for age z-scores during the early childhood were associated with cognition at 2 and 5 years of age in the same birth cohort, thus corrections were done for these in the current analysis [30,31]. Birth weight was not adjusted in final regression model, based on the published literature from our site which concluded that birth weight was not a predictor for head circumference at 12 months [4]. Both bivariate as well as multivariate regression was performed and beta-coefficients were expressed along with their $95 \%$ CI. Model fit was assessed using the adjusted $\mathrm{R}^{2}$ statistics. $P$ value lesser than 0.05 was considered as statistically significant. We performed data analysis using Stata version 13 (StataCorp. 2013. Stata Statistical Software. Release 13. College station, TX: StataCorp LP).

\section{Results}

After screening 301 pregnant mothers, 251 new-borns were recruited in the original birth-cohort. Excluded children were 50 , including eight children who had a sibling already registered, seven had medical comorbidities, one was a multiple pregnancy, five families had preexisting plan to migrate, nine mothers were not available for consent, ten families had combination of two or more of the above-mentioned reasons and ten mothers/ parents refused participation. Subsequent 2-year and 5year follow ups had 228 children and 212 children respectively. The loss to follow-up was mainly due to migration as illustrated in other articles, published from the same birth-cohort [30].

The Vellore birth-cohort had more than $80 \%$ of its families earning monthly income less than 1500 Indian rupees (20 USD) and 17\% of babies weighed less than $2.5 \mathrm{~kg}$ at birth. The median (range) raw score of maternal cognition was noted as $46.5(8-68)$ in the cohort. 
The cohort had girl predominance at birth (55\%). Cohort characteristics at two and five years were similar with respect to sex distribution and SES characteristics (Table 1). Compared to birth, more children became stunted, malnourished and wasted by two years of age and this change was significant (Table 1).

At birth, around one-third of children had $\mathrm{HC}<-2$ $\mathrm{SD}$, with this number increasing to $50 \%$ by 12 months. By 24 months, around $42.73 \%$ had HC between -2 and $-3 \mathrm{SD}$ and $8.81 \%$ of children had $\mathrm{HC}<-3 \mathrm{SD}$. The mean (SD) $\mathrm{HC}$ at 24 months was $44.9(1.2) \mathrm{cm}$. The mean (SD) BSID cognition raw score at two years was 59.5 (3.4). The WPPSI mean (SD) raw scores at 5 years for verbal, performance and processing speed were 37.97 (9.2), 48.18 (9.8) and 35.84 (18.4) respectively.

For cognitive development at two years of age, $\mathrm{HC}<-$ 3 SD was a significant predictor with an adjusted beta co-efficient of -2.21 (Table 2). The other factors included the mean blood lead levels and higher SES status. The $\mathrm{R}^{2}$ for the model was $7.6 \%$.

For cognitive assessment at five years of age, $R^{2}$ of models for verbal, performance and processing speed were $14.2,15.5$ and $17 \%$ respectively. $\mathrm{HC}<-3 \mathrm{SD}$ at two years of age predicted verbal (adjusted beta co-efficient of - 7.35) and performance (adjusted beta co-efficient of - 7.07) domains of cognition at five year; but not the processing speed (Table 3). The length for age z-scores at two years predicted processing speed at five years of age. Mean body iron levels and mother's cognition also was significantly associated with verbal, performance and processing speed of five-year cognition.

\section{Discussion}

This longitudinal prospective birth-cohort follow-up study from urban Vellore evaluated the effect of small $\mathrm{HC}$ on concurrently two-year cognition and predictively five-year cognition. $\mathrm{HC}<-3 \mathrm{SD}$ at two years of age was negatively associated with two-year cognition and predicted verbal and performance domains of five-year cognition, even after correction with SES, maternal cognition, mean iron and lead levels and length $\mathrm{z}$-scores.

Two years is considered the culmination of the first 1000 days of life, where rapid brain growth and development makes this period a critical window for future individual potential [18]. The next 1000 days of life till five years of age is also crucial as child continues to learn and develop during this period [19]. The 2-year HC can reflect the brain volume more accurately than in later years, as fontanelles and sutures are open during this period $[5,6]$.

Scattered studies have recommended that routine $\mathrm{HC}$ measurement is unnecessary in typically developing (TD) children, but necessary for children at risk $[5,7,8]$. A longitudinal study done in south west United Kingdom showed that children with small $\mathrm{HC}(<-2 \mathrm{SD})$ had increased risks of having lower intelligence at 8 years of

Table 1 Comparison of cohort characteristics during enrolment, year 2 and 5 of follow-up of MAL-ED cohort

\begin{tabular}{|c|c|c|c|c|}
\hline & Enrolment $(n=251)$ & 2 year $(n=228)$ & 5 year $(n=212)$ & $P$ value $^{b}$ \\
\hline Gender & & & & 0.960 \\
\hline Male & $113(45)$ & $105(46)$ & $98(46.2)$ & \\
\hline Female & $138(55)$ & $123(54)$ & $114(53.8)$ & \\
\hline SES & & & & 0.977 \\
\hline Low (WAMI <33rd percentile) & $71(30.2)$ & $71(31.14)$ & $65(30.66)$ & \\
\hline High (WAMI $\geq 33$ rd percentile) & $164(69.79)$ & $157(68.86)$ & $147(69.34)$ & \\
\hline Height-for-age $Z$ scores (HAZ) ${ }^{a}$ & & & & $<0.0001$ \\
\hline$>-2 S D$ & $210(83.67)$ & $126(55.51)$ & $150(70.75)$ & \\
\hline$<-2$ to $\geq-3 S D$ & $31(12.35)$ & $69(30.40)$ & $50(23.58)$ & \\
\hline$<-3 \mathrm{SD}$ & $10(3.98)$ & $32(14.10)$ & $12(5.66)$ & \\
\hline Weight-for-age Z scores (HAZ) ${ }^{a}$ & & & & 0.020 \\
\hline$>-2 S D$ & $194(77.29)$ & $146(64.32)$ & $149(70.28)$ & \\
\hline$<-2$ to $\geq-3 S D$ & $41(16.33)$ & $61(26.87)$ & $52(24.53)$ & \\
\hline$<-3 \mathrm{SD}$ & $16(6.37)$ & $20(8.81)$ & $11(5.19)$ & \\
\hline \multicolumn{5}{|l|}{ Weight-for-height Z scores ${ }^{a}$} \\
\hline$>-2 S D$ & $203(80.88)$ & $202(89)$ & $179(84.43)$ & 0.008 \\
\hline$<-2$ to $\geq-3 S D$ & $37(14.74)$ & $24(10.57)$ & $31(14.62)$ & \\
\hline$<-3 \mathrm{SD}$ & $11(4.38)$ & $1(0.44)$ & $2(0.94)$ & \\
\hline
\end{tabular}

a Only 227 children had information on WAZ, HAZ and weight-for-length scores at 2 years of follow-up

${ }^{\mathrm{b}}$ Test of significance was done using Chi-squared statistics 
Table 2 Predictors of cognitive development at 2 years of life in children of MAL-ED cohort

\begin{tabular}{|c|c|c|c|c|}
\hline \multirow[b]{2}{*}{ Predictors } & \multicolumn{2}{|l|}{ Univariate analysis $(n=227)$} & \multicolumn{2}{|c|}{ Multivariable analysis $(n=226)$} \\
\hline & Unadjusted beta co-efficient $^{d}$ & $P$ value & Adjusted beta co-efficient $^{d}$ & $P$ value \\
\hline \multicolumn{5}{|l|}{ Cognition domain $^{a}$} \\
\hline \multicolumn{5}{|c|}{ Head circumference z-scores at 24 months } \\
\hline$\geq-2 \mathrm{SD}$ & ref & - & ref & - \\
\hline$<-2$ to $\geq-3 \mathrm{SD}$ & $-0.22(-1.13-0.69)$ & 0.633 & $-0.16(-1.07-0.75)$ & 0.730 \\
\hline$<-3 \mathrm{SD}$ & $-2.57(-4.15--0.99)$ & 0.002 & $-2.21(-3.87--0.56)$ & 0.009 \\
\hline Sex (Female) & $-0.01(-0.90-0.87)$ & 0.977 & $-0.20(-1.09-0.69)$ & 0.653 \\
\hline Mean body iron ${ }^{\mathbf{b}}$ & $0.09(-0.03-0.20)$ & 0.131 & $0.05(-0.06-0.17)$ & 0.387 \\
\hline Mean body lead & $-0.11(-0.19--0.03)$ & 0.009 & $-0.10(-0.18--0.02)$ & 0.012 \\
\hline \multicolumn{5}{|l|}{ WAMI scores } \\
\hline$<33$ rd percentile & ref & - & ref & - \\
\hline$\geq 33$ rd percentile & $1.49(0.55-2.42)$ & 0.002 & $1.25(0.25-2.26)$ & 0.015 \\
\hline Mother's cognition & $0.03(-0.02-0.07)$ & 0.203 & $0.01(-0.04-0.05)$ & 0.779 \\
\hline Length for age z-scores at 24 months & $0.18(-0.29-0.63)$ & 0.466 & $-0.14(-0.63-0.33)$ & 0.551 \\
\hline
\end{tabular}

age and associated neurodevelopmental disorder; but $85 \%$ of children with small $\mathrm{HC}$ did not have any disorder 5]]. Routine $\mathrm{HC}$ measurements in Norwegian children were found useful in detecting hydrocephalus and cysts, when $\mathrm{HC}>+2 \mathrm{SD}$ [8]. A review analysis corroborated the above evidence [7]. However, this suggestion is in discordance with the AAP (http://brightfutures.aap.org) recommendation of measuring and plotting $\mathrm{HC}$ eight times in the first 2 years of age [1]. It must be noted that $\mathrm{HC}$ measurements in TD birth-cohorts have shown concurrent and predictive association with cognitive abilities. Analysis of the complete MAL-ED cohort from different LMIC countries, had shown early childhood $\mathrm{HC}$ growth patterns were associated with cognitive development at two years of age [2]. An Indian cohort study showed $\mathrm{HC}$ at birth was related to learning, memory and storage, and visuospatial abilities around 10 years of age [13]. Similarly $\mathrm{HC}$ at 2 years was associated with intelligence at both 4 and 8 years in a Bristol-based birth-cohort in the UK [14]. Reduced early childhood $\mathrm{HC}$ growth velocity had an increased risk of psychomotor delays in infancy as evidenced in both Israel [15] and Uruguay [16]. The current analysis adds further evidence to existing literature and concurs with AAP recommendation of $\mathrm{HC}$ measurement during routine immunisation visits. The Indian Academy of Pediatrics also recommends $\mathrm{HC}$ monitoring during immunisation visits till three years of age [32].

There is additional evidence to monitor $\mathrm{HC}$ routinely in children at risk, especially those born preterm, with low birth weight and those with antenatal teratogen exposure [9-12, 33, 34]. Brain volume, HC and cognition were found to be associated in a cross-sectional study of children with prenatal alcohol exposure in Canada [9]. In children born preterm, postnatal HC growth has been associated with developmental progress as evidenced in studies from Canada [10], Unites states [33], and Austria [34]. Among extremely low gestational age new-borns, microcephaly $(\mathrm{HC}<-2 \mathrm{SD})$ at two years was concurrently associated with both motor and cognitive impairments [33].

Most of the above studies have used the definition of $\mathrm{HC}<-2 \mathrm{SD}$ to evaluate associated developmental risk. Microcephaly has had differing definitions of $\mathrm{HC}<-2$ SD [35] and <-3 SD [36]. Many researchers have used the term 'severe microcephaly' for $\mathrm{HC}<-3 \mathrm{SD}$ [35]. The current cohort had almost one third of its children having $\mathrm{HC}<-2 \mathrm{SD}$ at birth, with this number climbing to $50 \%$ by one year of age. A detailed $\mathrm{HC}$ evaluation from this cohort has been published and showed that maternal and paternal $\mathrm{HC}$ predicted one-year infant $\mathrm{HC}$ [4]. Even in the current cohort of proportionately higher individuals with small $\mathrm{HC}$, microcephaly of $\mathrm{HC}<-3 \mathrm{SD}$ was associated concurrently and predictively with cognition at two and five years of age respectively. It might not be prudent to discard routine $\mathrm{HC}$ measurement in early childhood in general/paediatric practice, based on studies reporting microcephaly as $\mathrm{HC}<-2 \mathrm{SD}$. Future community based studies can explore further if $\mathrm{HC}<-3$ $\mathrm{SD}$ is a more appropriate definition of microcephaly.

Children in the present study from a LMIC setting were exposed to multiple environmental risks and had 
Table 3 Predictors of cognition at 5 years of life in children of MAL-ED cohort

\begin{tabular}{|c|c|c|c|c|}
\hline \multirow[b]{2}{*}{ Predictors } & \multicolumn{2}{|l|}{ Univariate analysis $(n=212)$} & \multicolumn{2}{|l|}{ Multivariable analysis $(n=212)$} \\
\hline & Unadjusted beta co-efficient $^{d}$ & $P$ value & Adjusted beta co-efficient $^{d}$ & $P$ value \\
\hline \multicolumn{5}{|l|}{ Verbal domain $^{a}$} \\
\hline \multicolumn{5}{|c|}{ Head circumference z-scores at 24 months } \\
\hline$\geq-2 \mathrm{SD}$ & ref & - & ref & - \\
\hline$<-2$ to $\geq-3 S D$ & $-1.97(-4.49-0.56)$ & 0.126 & $-1.58(-4.06-0.90)$ & 0.211 \\
\hline$<-3 \mathrm{SD}$ & $-9.08(-13.44--4.71)$ & $<0.001$ & $-7.35(-11.78--2.92)$ & 0.001 \\
\hline Sex (Female) & $1.12(-1.38-3.61)$ & 0.379 & $-0.26(-2.69-2.17)$ & 0.835 \\
\hline Mean body iron ${ }^{b}$ & $0.54(0.22-0.86)$ & 0.001 & $0.42(0.10-0.74)$ & 0.010 \\
\hline Mean body lead ${ }^{C}$ & $-0.10(-0.34-0.14)$ & 0.423 & $-0.07(-0.30-0.16)$ & 0.535 \\
\hline \multicolumn{5}{|l|}{ WAMI scores } \\
\hline$<33$ rd percentile & ref & - & ref & - \\
\hline$\geq 33$ rd percentile & $3.06(0.38-5.75)$ & 0.025 & $0.01(-2.74-2.74)$ & 0.998 \\
\hline Mother's cognition & $0.25(0.14-0.36)$ & $<0.001$ & $0.20(0.08-0.32)$ & 0.001 \\
\hline Length for age z-scores at 24 months & $1.35(0.08-2.63)$ & 0.037 & $0.45(-0.85-1.75)$ & 0.493 \\
\hline \multicolumn{5}{|l|}{ Performance domain ${ }^{a}$} \\
\hline \multicolumn{5}{|c|}{ Head circumference z-scores at 24 months } \\
\hline$\geq-2 \mathrm{SD}$ & ref & - & ref & - \\
\hline$<-2$ to $\geq-3 \mathrm{SD}$ & $-1.79(-4.50-0.92)$ & 0.194 & $-1.36(-3.99-1.28)$ & 0.311 \\
\hline$<-3 \mathrm{SD}$ & $-9.29(-14--4.6)$ & $<0.001$ & $-7.07(-11.77--2.36)$ & 0.003 \\
\hline Sex & $-0.32(-2.99-2.35)$ & 0.813 & $-1.91(-4.49-0.67)$ & 0.145 \\
\hline Mean body iron ${ }^{b}$ & $0.62(0.28-0.97)$ & $<0.001$ & $0.51(0.17-0.85)$ & 0.003 \\
\hline Mean body lead ${ }^{C}$ & $-0.24(-0.50-0.02)$ & 0.071 & $-0.22(-0.46-0.02)$ & 0.068 \\
\hline \multicolumn{5}{|l|}{ WAMI scores } \\
\hline$<33$ rd percentile & ref & - & ref & - \\
\hline$\geq 33$ rd percentile & $4.97(2.15-7.80)$ & 0.001 & $2.27(-0.64-5.18)$ & 0.125 \\
\hline Mother's cognition & $0.23(0.11-0.36)$ & $<0.001$ & $0.16(0.03-0.28)$ & 0.014 \\
\hline Length for age z-scores at 24 months & $1.22(-0.14-2.59)$ & 0.079 & $0.35(-1.03-1.73)$ & 0.617 \\
\hline
\end{tabular}

Processing speed domain ${ }^{a}$

Head circumference z-scores at 24 months

$$
\begin{aligned}
& \geq-2 S D \\
& <-2 \text { to } \geq-3 S D \\
& <-3 \text { SD }
\end{aligned}
$$

Sex

Mean body iron $^{\mathrm{b}}$

Mean body lead ${ }^{c}$

\section{WAMI scores}

$$
\begin{aligned}
& <33 \text { rd percentile } \\
& \geq 33 \text { rd percentile }
\end{aligned}
$$

Mother's cognition

Length for age $\mathrm{z}$-scores at $\mathbf{2 4}$ months ref

$-1.15(-6.31-4.00)$

$-14.09(-23.19--5.00)$

6.51 (1.56-11.47)

$1.25(0.61-1.90)$

$-0.16(-0.67-0.35)$

ref

$8.67(3.35-14.00)$

$0.47(0.25-0.70)$

$4.97(2.48-7.47)$ ref

$\begin{array}{lll}0.660 & 1.00(-3.90-5.89) & 0.688 \\ \mathbf{0 . 0 0 3} & -7.47(-16.39--1.46) & 0.101 \\ \mathbf{0 . 0 1 0} & 3.15(-1.65-7.95) & 0.197 \\ <\mathbf{0 . 0 0 1} & \mathbf{0 . 9 4}(\mathbf{0 . 3 0 - 1 . 5 6 )} & \mathbf{0 . 0 0 4} \\ 0.540 & -0.08(-0.55-0.38) & 0.727\end{array}$

- ref

$\mathbf{0 . 0 0 2} \quad 2.70(-2.72-8.13) \quad 0.327$

$<0.001 \quad 0.31(0.08-0.55) \quad 0.009$

$\begin{array}{lll}<0.001 & 3.48(0.92-6.04) & 0.008\end{array}$

${ }^{\mathrm{a}} \mathrm{R}^{2}$ value for verbal, performance and processing speed domains are $14.2,15.5$ and $17.0 \%$ respectively

${ }^{\mathrm{b}}$ Mean body iron levels were considered for the analysis and this is an average of body iron measurements at 7, 15 and 24 months of age in the cohort

c Mean blood lead levels were considered for the analysis and this is an average of blood lead levels measured at 15 and 24 months of age in the cohort

${ }^{\mathrm{d}}$ Beta co-efficient is presented along with $95 \%$ confidence interval 
high blood lead levels and low serum iron levels in early childhood [30, 37], necessitating close developmental monitoring. Many children in similar LMIC settings across the world are exposed to multiple risks in early childhood itself. Routine developmental assessments for all children in the community level in LMIC settings are difficult, time-consuming and resource-draining. In such settings, HC measurements can be quick, reproducible, easy, and utilise a simple tool such as a measuring tape. Routine $\mathrm{HC}$ measurements at immunisation/community clinics can identify children with abnormal HC. This group at risk can be more closely monitored and supported with additional community-based neurodevelopmental aids to optimise their developmental potential.

There were limitations for the current study. Although the cohort follow-up was about 90 and $85 \%$ at two and five years respectively, the sample size of the cohort was relatively smaller. $\mathrm{HC}$ measurements can be subjective, but periodic re-training and checks as done in this study can help to overcome this deficiency. The current study has many strengths including systematic follow-ups of a LMIC birth-cohort, robust data granularity, standardized anthropometric and cognitive assessments, haematological analysis from a national reference-level laboratory and good quality assurance/control measures.

\section{Conclusion}

Despite limitations, the current analysis done in a birthcohort follow-up study in a LMIC setting showed that $\mathrm{HC}<-3 \mathrm{SD}$ at 2 years of age was associated concurrently with 2-year cognition and predictively with 5 -year cognition; despite correction with SES, maternal cognition, early childhood iron and lead levels and length z-scores. This study highlights the utility of measuring early childhood HC in LMIC settings. Though there are differing definitions of microcephaly, $\mathrm{HC}<-3 \mathrm{SD}$ in typically developing populations can be defined as microcephaly, as these children are at risk of cognitive deficits. In resource poor settings, further studies need to confirm that microcephaly $(\mathrm{HC}<-3 \mathrm{SD})$ can be used as an early risk marker of child development and cognition; and advance current evidence with appropriate neurodevelopmental interventions in this vulnerable group.

\section{Supplementary Information}

The online version contains supplementary material available at https://doi. org/10.1186/s12887-021-02543-0.

Additional file 1: Supplementary Table 1. Multivariate analysis evaluating association of head circumference $<-2$ SD and cognition in children of MAL-ED cohort.

\section{Abbreviations}

BSID-III: Bayley Scales of Infant and Toddler Development-III; HC: Head circumference; LMIC: Low and middle income countries; MAL-ED: The
Etiology, Risk Factors and Interactions of Enteric Infections and Malnutrition and the Consequences for Child Health and Development; SES: Socioeconomic status; WAMI: Water and sanitation, assets, maternal education and total household income; WPPSI-III: Wechsler Preschool Primary Scales of Intelligence - third edition

\section{Acknowledgements}

The authors thank the participants, their families and staff of the MAL-ED Network project.

\section{Authors' contributions}

Drs. GK, SJ, AB, VRM, RR and BK are involved in the birth cohort study planning, recruitment and follow-up as well as in the planning, analysis, write-up and correction of the current study. Dr. TPM helped in data collection for the current study. Dr. PC is involved in Biochemical analysis and Dr. MS is involved in data analysis, write-up and corrections. All authors approved the final manuscript.

\section{Funding}

The Etiology, Risk Factors and Interactions of Enteric Infections and Malnutrition and the Consequence for Child Health and Development Project (MAL-ED) is carried out as a collaborative project supported by the Bill and Melinda Gates Foundation, the Foundation for the $\mathrm{NIH}$ and the National Institutes of Health/Fogarty International Center.

Availability of data and materials

MAL-ED data from all sites are deposited in the https://clinepidb.org.website.

\section{Ethics approval and consent to participate}

This study was conducted according to the guidelines laid down in the Declaration of Helsinki and all procedures involving human subjects/patients were approved by the Institutional Review Board, Christian Medical College, Vellore (IRB min no. 6789 dated 24.02.2009). Written informed consent was obtained from all participants' parents.

\section{Consent for publication}

Not applicable as there is no identifying information.

\section{Competing interests}

None.

\section{Author details}

${ }^{1}$ Developmental Paediatrics Unit, Christian Medical College, Vellore 632004, India. 'Wellcome research Unit, Christian Medical College, Vellore 632004, India. ${ }^{3}$ Community Health, Christian Medical College, Vellore 632004, India. ${ }^{4}$ Clinical Biochemistry, Christian Medical College, Vellore 632004, India. ${ }^{5}$ Low Cost Effective Care Unit, Christian Medical College, Vellore 632004, India.

Received: 7 November 2020 Accepted: 5 February 2021

Published online: 11 February 2021

\section{References}

1. American Academy of Pediatrics: Bright futures: Prevention and health promotion for infants, children, adolescents, and their families. In: Bright futures. edn. Edited by American Academy of Pediatrics. Elk Grove: American Academy of Pediatrics; 2015.

2. Scharf RJ, Rogawski ET, Murray-Kolb LE, Maphula A, Svensen E, Tofail F, et al. Early childhood growth and cognitive outcomes: findings from the MAL-ED study. Matern Child Nutr. 2018;14(3):e12584.

3. Maiti S, Ali KM, Ghosh D, Paul S. Assessment of head circumference among pre-school children of Midnapore town, West Bengal using WHO (2007) recommended cut-off points. Int J Prev Med. 2012;3(10):742-4.

4. Sindhu KN, Ramamurthy P, Ramanujam K, Henry A, Bondu JD, John SM, et al. Low head circumference during early childhood and its predictors in a semi-urban settlement of Vellore, Southern India. BMC Pediatr. 2019;19(1): 182.

5. Wright CM, Emond A. Head growth and neurocognitive outcomes. Pediatrics. 2015;135(6):e1393-8.

6. Ivanovic DM, Leiva BP, Pérez HT, Olivares MG, Díaz NS, Urrutia MS, et al. Head size and intelligence, learning, nutritional status and brain 
development. Head, IQ, learning, nutrition and brain. Neuropsychologia. 2004;42(8):1118-31.

7. Sniderman A. Abnormal head growth. Pediatr Rev. 2010;31(9):382-4.

8. Zahl SM, Wester K. Routine measurement of head circumference as a tool for detecting intracranial expansion in infants: what is the gain? A nationwide survey. Pediatrics. 2008;121(3):e416-20.

9. Treit S, Zhou D, Chudley AE, Andrew G, Rasmussen C, Nikkel SM, et al. Relationships between head circumference, brain volume and cognition in children with prenatal alcohol exposure. PLoS One. 2016;11(2):e0150370.

10. Raghuram K, Yang J, Church PT, Cieslak Z, Synnes A, Mukerji A, et al. Head Growth Trajectory and Neurodevelopmental Outcomes in Preterm Neonates. Pediatrics. 2017;140(1):e20170216.

11. Cheong JLY, Hunt RW, Anderson PJ, Howard K, Thompson DK, Wang HX, et al. Head growth in preterm infants: correlation with magnetic resonance imaging and neurodevelopmental outcome. Pediatrics. 2008;121(6):e153440.

12. Scharf RJ, Stroustrup A, Conaway MR, DeBoer MD. Growth and development in children born very low birthweight. Arch Dis Child Fetal Neonatal Ed. 2016;101(5):F433-8.

13. Veena SR, Krishnaveni GV, Wills AK, Kurpad AV, Muthayya S, Hill JC, et al. Association of birthweight and head circumference at birth to cognitive performance in 9- to 10-year-old children in South India: prospective birth cohort study. Pediatr Res. 2010;67(4):424-9.

14. Gale CR, O'Callaghan FJ, Bredow M, Martyn CN. The influence of head growth in fetal life, infancy, and childhood on intelligence at the ages of 4 and 8 years. Pediatrics. 2006;118(4):1486-92.

15. Tal G, Cohen A, Habib S, Tirosh E. Decreased head circumference velocity as related to developmental deficit in infancy. Pediatr Neurol. 2012;47(5):341-4.

16. Bove I, Miranda T, Campoy C, Uauy R, Napol M. Stunting, overweight and child development impairment go hand in hand as key problems of early infancy: Uruguayan case. Early Hum Dev. 2012;88(9):747-51.

17. Bartholomeusz HH, Courchesne E, Karns CM. Relationship between head circumference and brain volume in healthy normal toddlers, children, and adults. Neuropediatrics. 2002;33(5):239-41.

18. Biesalski HK. The 1,000-day window and cognitive development. World Rev Nutr Diet. 2016;115:1-15.

19. Georgiadis A, Penny ME. Child undernutrition: opportunities beyond the first 1000 days. Lancet Public Health. 2017;2(9):e399.

20. MAL-ED Network Investigators: The MAL-ED study: a multinational and multidisciplinary approach to understand the relationship between enteric pathogens, malnutrition, gut physiology, physical growth, cognitive development, and immune responses in infants and children up to 2 years of age in resource-poor environments. Clin Infect Dis. 2014;59 Suppl 4: S193-206.

21. John SM, Thomas RJ, Kaki S, Sharma SL, Ramanujam K, Raghava MV, et al. Establishment of the MAL-ED birth cohort study site in Vellore, southern India. Clin Infect Dis. 2014;59(Suppl 4):S295-9.

22. World Health Organization. WHO child growth standards: methods and development: length/height-for-age, weight-for-age, weight-for-length, weight-for-height and body mass index-for-age. Geneva, Switzerland: World Health Organization; 2006.

23. World Health Organization: Child Growth Standards. Head circumferenceforage. Available from: http://www.who.int/childgrowth/standards/hc_for_age/ en/. Accessed 21 Aug 2020.

24. Bayley N. Bayley scales of infant and toddler development III. San Antonio, TX: Psychological Corp; 2005.

25. Murray-Kolb LE, Rasmussen ZA, Scharf RJ, Rasheed MA, Svensen E, Seidman $J C$, et al. The MAL-ED cohort study: methods and lessons learned when assessing early child development and caregiving mediators in infants and young children in 8 low- and middle-income countries. Clin Infect Dis. 2014; 59(Suppl 4):S261-72

26. Wechsler D. The Wechsler preschool and primary scale of intelligence, third edition (WPPSI-III). San Antonio, TX: The Psychological Corporation; 2002.

27. Psaki SR, Seidman JC, Miller M, Gottlieb M, Bhutta ZA, Ahmed T, et al. Measuring socioeconomic status in multicountry studies: results from the eight-country MAL-ED study. Popul Health Metr. 2014;12(1):8. https://doi. org/10.1186/1478-7954-12-8 2014.

28. Raven J, Raven JC, Court JH. Manual for Raven's progressive matrices and vocabulary scales. San Antonio, TX: Harcourt Assessment; 2003.

29. Cook JD, Flowers $\mathrm{CH}$, Skikne BS. The quantitative assessment of body iron. Blood. 2003;101(9):3359-64.
30. Koshy B, Srinivasan M, Zachariah SM, Karthikeyan AS, Roshan R, Bose A, et al. Body iron and lead status in early childhood and its effects on development and cognition: a longitudinal study from urban Vellore. Public Health Nutr. 2020:23(11):1896-1906.

31. McCormick BJJ, Richard SA, Caulfield LE, Pendergast LL, Seidman JC, Koshy $B$, et al. Early life child micronutrient status, maternal reasoning, and a nurturing household environment have persistent influences on child cognitive development at age 5 years: results from MAL-ED. J Nutr. 2019; 149(8):1460-9.

32. Khadilkar W, Khadilkar AV, Choudhury P, Agarwal KN, Ugra D, Shah NK. IAP growth monitoring guidelines for children from birth to 18 years. Indian Pediatr. 2007;44(3):187-97.

33. Kuban KCK, Allred EN, O'Shea TM, Paneth N, Westra S, Miller C, et al. Developmental correlates of head circumference at birth and two years in a cohort of extremely low gestational age newborns. J Pediatr. 2009;155(3): 344-9 e393.

34. Neubauer V, Griesmaier E, Pehböck-Walser N, Pupp-Peglow U, KiechlKohlendorfer U. Poor postnatal head growth in very preterm infants is associated with impaired neurodevelopment outcome. Acta Paediatr. 2013; 102(9):883-8.

35. Harris SR. Measuring head circumference: update on infant microcephaly. Canadian family physician Medecin de famille canadien. 2015:61(8):680-4.

36. Kliegman R. Nelson textbook of Pediatrics. Edition 21. Philadelphia, PA: Elsevier; 2020.

37. Mohan VR, Sharma S, Ramanujam K, Babji S, Koshy B, Bondu JD, et al. Effects of elevated blood lead levels in preschool children in urban Vellore. Indian Pediatr. 2014;51(8):621-5.

\section{Publisher's Note}

Springer Nature remains neutral with regard to jurisdictional claims in published maps and institutional affiliations.

Ready to submit your research? Choose BMC and benefit from:

- fast, convenient online submission

- thorough peer review by experienced researchers in your field

- rapid publication on acceptance

- support for research data, including large and complex data types

- gold Open Access which fosters wider collaboration and increased citations

- maximum visibility for your research: over $100 \mathrm{M}$ website views per year

At $\mathrm{BMC}$, research is always in progress.

Learn more biomedcentral.com/submissions 